\title{
The Correction Methods of the Intestinal Microflora in Chronic Colonic Stasis by Siphon Enema and Probiotics as a Means of the Hirschsprung-associated Enterocolitis Prevention
}

Galymzhan Burayev*, Medet Khamitov${ }^{1}$, Vassily Lozovoy ${ }^{1}$, Rasulbek Aipov${ }^{1}$, Elena Lozovaya ${ }^{1}$, Lyudmila Akhmaltdinova ${ }^{2}$, Kamshat Burayeva ${ }^{3}$

${ }^{1}$ Department of Pediatric Surgery, Astana Medical University, Nur-Sultan, Kazakhstan; ${ }^{2}$ Department of Immunology, Karaganda State Medical University, Karaganda, Kazakhstan; ${ }^{3}$ Department of Therapy, Khoja Akhmet Yassawi International, KazakhTurkish University, Turkestan, Kazakhstan

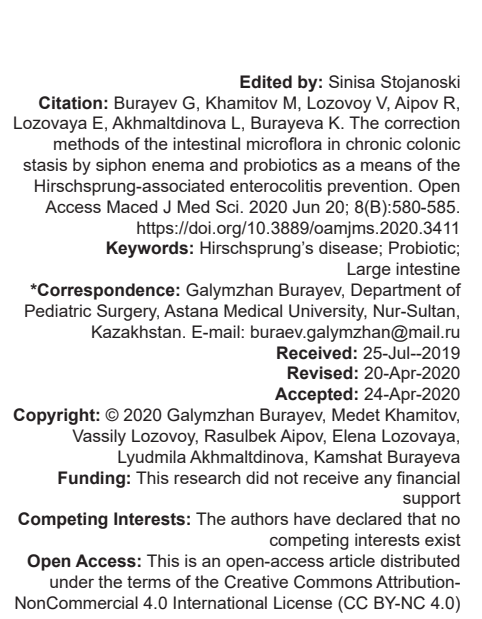

\section{Introduction}

Hirschsprung's disease is a congenital malformation of the colon with a lack or absence of ganglion cells in the intestinal segment, manifested mainly in symptoms of chronic colonic stasis. The reported incidence of the disease is 1:5000 among newborns [1], [2], [3]. Despite improved surgical results, complications of the disease occur with a frequency of $22.7 \%$ to $38.5 \%$ [4].

The most severe complication of Hirschsprung's disease is Hirschsprung-associated enterocolitis (HAEC). HAEC occurs against the background of pronounced local immune perturbation of the intestinal wall and microbiocenosis disturbance, resulting in the development of pathogenic microflora and leading to the disorder of microcirculation with subsequent perforation of the intestinal wall and development of peritonitis [5], [6], [7], [8]. Complications can develop both before and after surgical treatment. The incidence of enterocolitis before surgery varies from $6 \%$ to $50 \%$ of cases, while after surgery - from $2 \%$ to $35 \%$ [9]. The lack of methods to correct these disorders leads to complications in the anastomosis zone in $10-15 \%$ of cases [10]. The mortality rate remains high $-2.6-12.0 \%$, especially in young children - 31-35\% [11], [12], [13].

The available data show that the prevention of HAEC remains a relevant issue. This work aimed at studying the state of the intestinal microflora in the context of chronic colonic stasis and assessing the methods of its correction by siphon enema and probiotics (bifidumbacterin and lactobacterin) to prevent the development of HAEC. The proposed method was not used before, so there are no scientific studies on the peculiarities of implication and the obtained results.

\section{Materials and Methods}

The prospective study was conducted in the Astana City Children's Hospital No. 2, involving 60 
children who applied for medical help with symptoms of chronic constipation. They were admitted to the hospital in a planned or emergency manner with suspected Hirschsprung's disease during the period from 2015 to 2017, after approval of the Ethics Committee (Extract from the No. 5 min of the Ethics Committee meeting).

The age of the children ranged from 2 months to 14 years. There were 36 boys $(60 \%)$ and 24 girls (40\%). The distribution of patients by age and gender is presented in Table 1.

Table 1: Distribution of children by age and gender

\begin{tabular}{lll}
\hline Age/gender & Boys & Girls \\
\hline $1-6$ months & 2 & 1 \\
$6-12$ months & 3 & 1 \\
$1-3$ years old & 8 & 7 \\
$3-6$ years old & 11 & 9 \\
$6-11$ years old & 10 & 6 \\
Older than 11 years & 2 & 0 \\
Total & 36 & 24 \\
\hline
\end{tabular}

For diagnostic purposes, all the children underwent an X-ray contrast study of the large intestine (irrigography). According to the results of irrigography, they were divided into the following nosological forms (Figure 1).

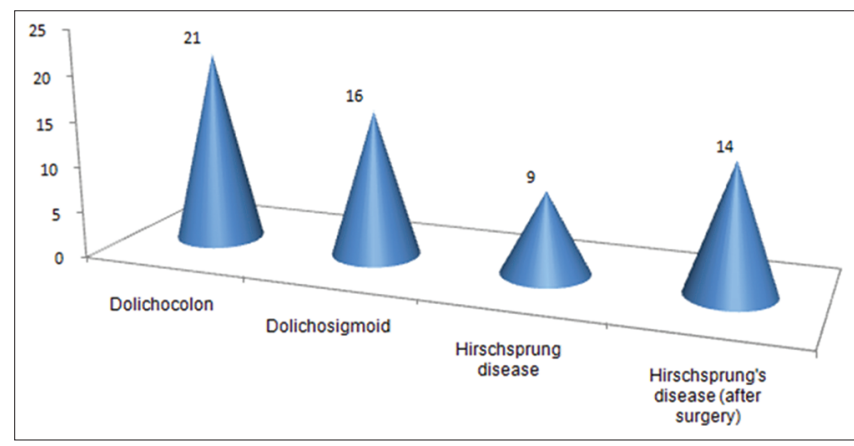

Figure 1: Results of irrigography

The study was conducted in two stages:

\section{$1^{\text {st }}$ stage - analysis of a series of cases}

To study the effect of bowel cleansing by means of a siphon enema on the quantitative composition of the intestinal microflora in chronic colonic stasis, a series of cases have been analyzed. The bacteriological examination of stool samples showed that the number of normal intestinal microflora microorganisms (bifidobacteria, lactic acid bacteria, and $E$. coli with normal enzyme activity) in patients with symptoms of chronic colonic stasis was below the minimum normal values. Before the administration of siphon enemas, such opportunistic microorganisms as hemolyzing Escherichia coli, Staphylococcus aureus, lactose-negative E. coli, enterococci, Proteus mirabilis, and Candida yeast-like fungi were detected during the bacteriological examination of stool samples. To prepare the large intestine for irrigography and surgical intervention, siphon enemas (with $1 \%$ sodium chloride at room temperature) were administered to 20 patients with symptoms of chronic constipation to clean the intestines. The volume of fluid for enema was determined by the age of the patients. The patients had indications for siphon enemas implication like complaints about the absence or delay of stool for several days over a long period of time with a lack of effect from a cleansing enema in the anamnesis.

Cleansing enemas were given to patients under the age of 2 months. The average duration of preparation was 4.2 days.

\section{$2^{\text {nd }}$ stage - nonrandomized controlled research}

At this stage, based on the results of a series of cases, the quantitative composition of the intestinal microflora was corrected. Forty patients with symptoms of chronic constipation were equally divided into two groups (with implementing of the randomization of patients using a random number table).

The main group involved 20 children. In this group, to prepare for irrigography and surgical intervention, the intestinal microflora was corrected by the proposed method. Probiotics were administered orally and by an enema with direct irrigation of the colon cavity at an age dosage given in the instructions: For children up to a year - 1 pack 2-3 times a day, from a year and older - 1 pack 3-4 times a day.

The control group involved 20 children. They received probiotics only enterally.

Bifidumbacterin (containing live bifidobacteria at no $<50$ million CFU/g) and lactobacterin (containing at least 10 million live acidophilic lactobacilli) preparations were used as a probiotic medicine in the form of powder:

- Bifidumbacterin forte regulates the balance of the intestinal microflora. The effect comes from the high concentration of bifidobacteria occluded on absorbent carbon particles, being antagonists of a wide range of pathogenic (including Shigella spp., Salmonella spp., and S. aureus), and opportunistic microorganisms (including Proteus spp. and Klebsiella spp.). It is produced by JSC "Firma Vitafarma," Russia. - Lactobacterin (powder) includes live lactobacilli with antagonistic activity against a wide range of pathogenic and opportunistic bacteria (including staphylococci, Proteus, and enteropathogenic $E$. coli), normalizes the digestive activity of the gastrointestinal tract, improves metabolic processes, and promotes the restoration of natural immunity. It is produced by Microgen NPO, Russia.

The average duration of treatment was 11.3 days for the main group and 11.2 days for the control group.

The statistical processing of the results was carried out using Student's test for dependent and independent samples by means of the BioStat Software. 


\section{Results}

After the administration of siphon enemas at the first stage of the survey (is described in details above), the bacteriological examination of stool samples showed a marked decrease in the number of beneficial microorganisms of the intestinal microflora with a statistically significant difference $(p<0.001)$ (Table 2).

As can be seen from Table 2, in the period after the administration of siphon enemas, there was a decrease in the number and CFU/g concentrations of opportunistic microorganisms in the intestine (hemolyzing E. coli, S. aureus, lactose-negative E. coli, enterococci, and Candida yeast-like fungi). At the same time, there was a decrease in the number of beneficial microorganisms (bifidobacteria, lactic acid bacteria, and $E$. coli with normal enzyme activity).

At the second stage in the period before the correction of the quantitative composition of the intestinal microflora, the results of the bacteriological examination of stool samples in both groups corresponded to the results of the first stage before the administration of siphon enemas: A decrease in the number of microorganisms of the obligate intestinal microflora and the detection of certain species of opportunistic microorganisms.

The normalization of the number of beneficial microorganisms and the reduction in the number of opportunistic microorganisms (Table 3) was observed in patients of the main group after treatment by the developed method.
After treatment, the concentration of all kinds of beneficial microorganisms in the intestine, namely bifidobacteria, lactic acid bacteria, and $E$. coli with normal enzyme activity, increased to normal values with a statistically significant difference: $p<0.001, p<0.01$, and $p<0.05$, respectively. A statistically significant decrease in the concentration of opportunistic enterobacteria in the intestine such as hemolytic active $E$. coli, lactosenegative $E$. coli, and $P$. mirabilis was revealed.

In the bacteriological examination of stool samples obtained after treatment in the control group of patients, despite a slight improvement in the ratio of beneficial microorganisms in the intestine, the number of opportunistic microorganisms ( $S$. aureus, Klebsiella pneumoniae, Citrobacter diversus, and $P$. mirabilis) increased (Table 4).

Despite treatment, there was a decrease of bifidobacteria with obvious statistical significance ( $p<0.001)$. Other types of beneficial microorganisms (lactic acid bacteria, E. coli with normal enzyme activity) increased. However, the statistical processing revealed that these parameters had no significant difference $(p>0.05)$ and did not reach the normal level $(p<0.001)$.

When analyzing the number of opportunistic enterobacteria in the control stool, one can note an increase of pathogens above the norm and concentration in the intestine with the appearance of associations between them with a statistically significant difference $(p<0.001)$

A comparative analysis of the results of the bacteriological examination of the intestinal microflora in patients of the main and control groups revealed that the

Table 2: Results of the study of the intestinal microflora before and after administration of siphon enemas

\begin{tabular}{|c|c|c|c|c|}
\hline \multirow[t]{2}{*}{ Microorganisms } & \multirow[t]{2}{*}{$\begin{array}{l}\text { Norm in children (Industry standard } \\
91500.11 .0004-2003 \text { ) }\end{array}$} & $\begin{array}{l}\text { Number of microorganisms before } \\
\text { administration of siphon enemas }(n=20)\end{array}$ & $\begin{array}{l}\text { Number of microorganisms after } \\
\text { administration of siphon enemas }(n=20)\end{array}$ & \multirow[t]{2}{*}{$p$} \\
\hline & & $\mathrm{M} \pm \mathrm{m}$ & $\mathrm{M} \pm \mathrm{m}$ & \\
\hline Bifidobacteria & $10^{9}-10^{11} \mathrm{CFU} / \mathrm{g}$ & $2,377 \times 10^{8} \pm 9,0 \times 10^{7} \mathrm{CFU} / \mathrm{g}^{\mathrm{m}}$ & $2,2375 \times 10^{6} \pm 9,17 \times 10^{5} \mathrm{CFU} / \mathrm{g}^{\mathrm{Im}}$ & $p<0,001$ \\
\hline Lactic acid bacteria & $10^{6}-10^{8} \mathrm{CFU} / \mathrm{g}$ & $5,95 \times 10^{5} \pm 1,05 \times 10^{5} \mathrm{CFU} / \mathrm{g}^{\ldots}$ & $5,455 \times 10^{4} \pm 1,08 \times 10^{4} \mathrm{CFU} / \mathrm{g}^{\prime}$ & $p<0,001$ \\
\hline E. coli with normal enzyme activity & $10^{7}-10^{8} \mathrm{CFU} / \mathrm{g}$ & $3,25 \times 10^{6} \pm 9,24 \times 10^{5} \mathrm{CFU} / \mathrm{g}^{\ldots \ldots}$ & $2,8 \times 10^{5} \pm 8,4 \times 10^{4} \mathrm{CFU} / \mathrm{g}^{\ldots \ldots}$ & $p<0,01$ \\
\hline \multirow[t]{2}{*}{ Opportunistic enterobacteria } & $\begin{array}{l}\text { Norm in children (Industry standard } \\
91500.11 .0004-2003 \text { ) }\end{array}$ & $\begin{array}{l}\text { Number of patients with bacteria above } \\
\text { the norm }\end{array}$ & $\begin{array}{l}\text { Number of patients with bacteria above } \\
\text { the norm }\end{array}$ & $\mathrm{p}$ \\
\hline & & $\mathrm{CFU} / \mathrm{g}$ & $\mathrm{CFU} / \mathrm{g}$ & \\
\hline Hemolytic active $E$. coli & 0 & $1(2)$ & - & $p=0,000$ \\
\hline S. aureus & 0 & $1(2)$ & - & $p=0,000$ \\
\hline Candida yeast-like fungi & $<10^{3}-10^{4}$ & $2(10)$ & $1(2)$ & $p>0,05$ \\
\hline Lactose-negative E. coli & $<10^{5}$ & $1(2)$ & - & $p=0,000$ \\
\hline Enterococci and P. mirabilis & 0 & $1(2)$ & $10^{4^{* * *}}$ & $p<0,001$ \\
\hline
\end{tabular}

Table 3: Results of the study of the intestinal microflora before and after treatment of patients in the main group

\begin{tabular}{|c|c|c|c|c|c|}
\hline \multirow[t]{2}{*}{ Microorganisms } & \multirow[t]{2}{*}{$\begin{array}{l}\text { Norm in children (Industry standard } \\
91500.11 .0004-2003)\end{array}$} & $\begin{array}{l}\text { Number of microorganisms } \\
\text { before treatment }(n=20)\end{array}$ & $\begin{array}{l}\text { Number of microorganisms after } \\
\text { treatment }(n=20)\end{array}$ & \multicolumn{2}{|l|}{$p$} \\
\hline & & $\mathrm{M} \pm \mathrm{m}$ & $\mathrm{M} \pm \mathrm{m}$ & & \\
\hline Bifidobacteria & $10^{9}-10^{11} \mathrm{CFU} / \mathrm{g}$ & $1,2025 \times 10^{8} \pm 6,9 \times 10^{7} \mathrm{CFU} / \mathrm{g}^{\mathrm{m}}$ & $1,18 \times 10^{9} \pm 4,85 \times 10^{8} \mathrm{CFU} / \mathrm{g}$ & $p<0,001$ & \\
\hline Lactic acid bacteria & $10^{6}-10^{8} \mathrm{CFU} / \mathrm{g}$ & $7,75 \times 10^{5} \pm 8,8 \times 10^{4} \mathrm{CFU} / \mathrm{g}^{\ldots \#}$ & $2,62 \times 10^{7} \pm 8 \times 10^{6} \mathrm{CFU} / \mathrm{g}$ & $p<0,01$ & \\
\hline E. coli with normal enzyme activity & $10^{7}-10^{8} \mathrm{CFU} / \mathrm{g}$ & $2,53 \times 10^{6} \pm 9,67 \times 10^{5} \mathrm{CFU} / \mathrm{g}^{\# \#}$ & $3,205 \times 10^{7} \pm 9 \times 10^{6} \mathrm{CFU} / \mathrm{g}$ & $p<0,05$ & \\
\hline Opportunistic enterobacteria & $<10^{4}$ & $\begin{array}{l}\text { Number of patients with } \\
\text { bacteria above the norm }\end{array}$ & $\begin{array}{l}\text { Number of patients with bacteria above } \\
\text { the norm }\end{array}$ & $p$ & \\
\hline & & $\mathrm{CFU} / \mathrm{g}$ & abs (\%) & abs $(\%)$ & \\
\hline Hemolytic active $E$. coli & 0 & $10^{7^{* * *}}$ & $2(10)$ & $1(5)$ & $p>0,05$ \\
\hline S. aureus & 0 & $10^{4}$ & $1(5)$ & - & $p=0,000$ \\
\hline Lactose-negative $E$. coli & $<10^{4}$ & $10^{7 * *}$ & $1(5)$ & $1(5)$ & $p>0,05$ \\
\hline P. mirabilis & $<10^{4}$ & $10^{6^{* *}}$ & $1(5)$ & $1(5)$ & $p>0,05$ \\
\hline Candida yeast-like fungi and enterococci & 0 & $10^{5}$ & $1(5)$ & - & $p=0,000$ \\
\hline
\end{tabular}


number of microorganisms in stool samples significantly differed in each group with a statistically significant difference. The data obtained in this comparative analysis for the main and control groups are presented in Table 5 .

Table 5 shows that before treatment, there was no statistically significant difference of beneficial and pathogenic intestinal microorganisms between groups $(p>0.05)$. While in the period after treatment, in patients of the main group, in comparison with the control group, the number of beneficial microorganisms was higher, and there was a decrease in the number of opportunistic enterobacteria $(p<0.001)$.

When studying the number of microorganisms in the intestinal microflora and comparing them with the degree of dysbiosis (the degrees of dysbiosis were determined according to the criteria of the sectoral standard of the Ministry of Health of Russian Federation "Protocol of treatment. Intestinal dysbiosis" [14]), the following results were revealed (Figure 2):

- Before treatment the $1^{\text {st }}$-degree intestinal dysbiosis was detected in 14 patients of the main group $(70 \%)$ and in 15 patients of the control group $(75 \%) ; 2^{\text {nd }}$-degree dysbiosis was detected in the remaining six patients of the main group (30\%) and in the remaining five patients of the control group (25\%);

- $\quad$ After treatment in the main group, the number of patients with $1^{\text {st }}$-degree intestinal dysbiosis decreased to three cases $(15 \%)$, and the number of patients with $2^{\text {nd }}$-degree dysbiosis decreased twofold - three patients $(15 \%)$, while the state of the intestinal microflora in the remaining 14 patients ( $70 \%$ of cases) corresponded to the norm;

- In the same period after treatment in the control group, the number of patients with $1^{\text {st }}$-degree intestinal dysbiosis decreased to four patients $(20 \%)$, due to an increase in patients with $2^{\text {nd }}$-degree dysbiosis (the remaining 16 patients $-80 \%$ of cases). No patients had the normal parameters of the intestinal flora.

Figure 2 shows that in the period before treatment, there was no statistically significant difference

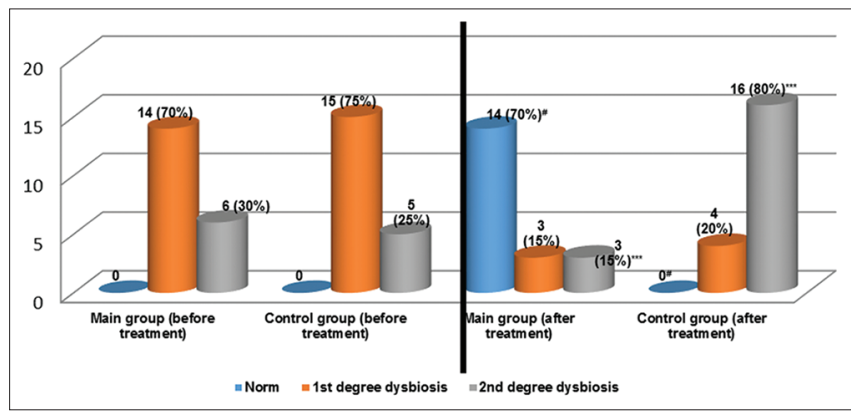

Figure 2: Distribution of patients of the main and control group by the degree of intestinal dysbiosis before and after treatment

Note: \# - degree of reliability at $p=0.000$ in patients of the main and control groups of the normal value; ${ }^{* * *}-$ degree of reliability at $p<0.001$ in patients of the main and control group with $2^{\text {nd }}$-degree intestinal dysbiosis).

Table 4: Results of the study of the intestinal microflora before and after treatment of patients in the control group

\begin{tabular}{|c|c|c|c|c|c|c|}
\hline Microorganisms & $\begin{array}{l}\text { Norm in children } \\
\text { (Industry standard 91500.11.0004-2003) }\end{array}$ & \multicolumn{2}{|c|}{$\begin{array}{l}\text { Number of microorganisms before } \\
\text { treatment }(n=20)\end{array}$} & \multicolumn{2}{|c|}{$\begin{array}{l}\text { Number of microorganisms after } \\
\text { treatment }(n=20)\end{array}$} & $p$ \\
\hline Bifidobacteria & $10^{9}-10^{11} \mathrm{CFU} / \mathrm{g}$ & \multicolumn{2}{|c|}{$1,207 \times 10^{8} \pm 6,9 \times 10^{7} \mathrm{CFU} / \mathrm{g}^{\prime \prime \#}$} & \multicolumn{2}{|c|}{$2,577 \times 10^{6} \pm 9,19 \times 10^{5} \mathrm{CFU} / \mathrm{g}$} & $p<0,001$ \\
\hline Lactic acid bacteria & $10^{6}-10^{8} \mathrm{CFU} / \mathrm{g}$ & \multicolumn{2}{|c|}{$6,3 \times 10^{5} \pm 1,05 \times 10^{5} \mathrm{CFU} / \mathrm{g}^{\# \# \#}$} & \multicolumn{2}{|c|}{$8,8 \times 10^{5} \pm 1,08 \times 10^{5} \mathrm{CFU} / \mathrm{g}^{\ldots \ldots}$} & $p>0,05$ \\
\hline E. coli with normal enzyme activity & $10^{7}-10^{8} \mathrm{CFU} / \mathrm{g}$ & \multicolumn{2}{|c|}{$2,08 \times 10^{6} \pm 7,84 \times 10^{5} \mathrm{CFU} / \mathrm{g}^{\mathrm{m}}$} & \multicolumn{2}{|c|}{$5,015 \times 10^{6} \pm 8,86 \times 10^{5} \mathrm{CFU} / \mathrm{g}^{\mathrm{m}}$} & $p>0,05$ \\
\hline \multirow[t]{2}{*}{ Opportunistic enterobacteria } & $<10^{4}$ & \multicolumn{2}{|c|}{$\begin{array}{l}\text { Number of patients with bacteria } \\
\text { above the norm }\end{array}$} & \multicolumn{2}{|c|}{$\begin{array}{l}\text { Number of patients with bacteria } \\
\text { above the norm }\end{array}$} & $\mathrm{p}$ \\
\hline & & $\mathrm{CFU} / \mathrm{g}$ & abs (\%) & $\mathrm{CFU} / \mathrm{g}$ & abs $(\%)$ & \\
\hline Hemolytic active $E$. coli & $<10^{4}$ & - & - & $10^{5}$ & $2(10)$ & $p=0,000$ \\
\hline S. aureus & $<10^{4}$ & $10^{4}$ & $2(10)$ & - & - & $p=0,000$ \\
\hline Candida yeast-like fungi & $<10^{3}-10^{4}$ & $10^{5}$ & $2(10)$ & $10^{6}$ & $3(15)^{\star \star \star}$ & $p>0,05$ \\
\hline Lactose-negative $E$. coli & $<10^{4}$ & - & - & $10^{5}$ & $2(10)$ & $p=0,000$ \\
\hline Enterococci & $<10^{5}-10^{7}$ & $10^{7}$ & $1(2)$ & $10^{8^{8+*}}$ & $3(15)^{\star \star \star}$ & $p<0,001$ \\
\hline K. pneumoniae & $<10^{4}$ & - & - & $10^{5}$ & $1(2)$ & $\mathrm{p}=0,000$ \\
\hline C. diversus & $<10^{4}$ & _- & _- & $10^{5}$ & $1(2)$ & $p=0,000$ \\
\hline P. mirabilis & $<10^{4}$ & - & - & $10^{6}$ & $1(2)$ & $p=0,000$ \\
\hline S. aureus and K. pneumoniae & 0 & - & - & $10^{5}$ & $2(10)$ & $\mathrm{p}=0,000$ \\
\hline C. diversus and P. mirabilis & 0 & - & - & $10^{5}$ & $1(2)$ & $\mathrm{p}=0,000$ \\
\hline \multicolumn{7}{|c|}{ 1. \#-degree of reliability in relation to the norm: } \\
\hline \multicolumn{7}{|l|}{-\#- degree of reliability at $p<0,05$} \\
\hline \multicolumn{7}{|l|}{ - degree of reliability at $p<0,01$} \\
\hline \multicolumn{7}{|l|}{ - \#\# - degree of reliability at $p<0,001$} \\
\hline \multirow{2}{*}{\multicolumn{7}{|c|}{ 2.* - degree of reliability of the values expressed in $\mathrm{CFU} / \mathrm{g}$ and in percentage (\%) when compared with the corresponding values of another group: }} \\
\hline & & & & & & \\
\hline$-{ }^{*}$ - degree of reliability at $p<0,05$ & & & & & & \\
\hline
\end{tabular}

Table 5: Comparative analysis of the results of the bacteriological examination of the intestinal microflora in patients of the main and control groups

\begin{tabular}{|c|c|c|c|c|c|c|}
\hline \multirow[t]{3}{*}{ Microorganisms } & \multicolumn{2}{|c|}{ Number of microorganisms before treatment $(n=20)$} & \multirow[t]{3}{*}{$\mathrm{p}$} & \multicolumn{2}{|c|}{ Number of microorganisms after treatment $(n=20)$} & \multirow[t]{3}{*}{$p$} \\
\hline & Main group & Control group & & Main group & Control group & \\
\hline & $\mathrm{M} \pm \mathrm{m}$ & $\mathrm{M} \pm \mathrm{m}$ & & $\mathrm{M} \pm \mathrm{m}$ & $\mathrm{M} \pm \mathrm{m}$ & \\
\hline Bifidobacteria & $1,2025 \times 10^{8} \pm 6,9 \times 10^{7} \mathrm{CFU} / \mathrm{g}$ & $1,207 \times 10^{8} \pm 6,9 \times 10^{7} \mathrm{CFU} / \mathrm{g}$ & $p>0,05$ & $1,18 \times 10^{9} \pm 4,85 \times 10^{8} \mathrm{CFU} / \mathrm{g}$ & $2,577 \times 10^{6} \pm 9,19 \times 10^{5} \mathrm{CFU} / \mathrm{g}$ & $\mathrm{p}<0,001$ \\
\hline $\begin{array}{l}\text { Lactic acid } \\
\text { bacteria }\end{array}$ & $7,75 \times 10^{5} \pm 8,8 \times 10^{4} \mathrm{CFU} / \mathrm{g}$ & $6,3 \times 10^{5} \pm 1,05 \times 10^{5} \mathrm{CFU} / \mathrm{g}$ & $p>0,05$ & $2,62 \times 10^{7} \pm 8 \times 10^{6} \mathrm{CFU} / \mathrm{g}$ & $8,8 \times 10^{5} \pm 1,08 \times 10^{5} \mathrm{CFU} / \mathrm{g}$ & $\mathrm{p}<0,001$ \\
\hline $\begin{array}{l}\text { E. coli with normal } \\
\text { enzyme activity }\end{array}$ & $2,53 \times 10^{6} \pm 9,67 \times 10^{5} \mathrm{CFU} / \mathrm{g}$ & $2,08 \times 10^{6} \pm 7,84 \times 10^{5} \mathrm{CFU} / \mathrm{g}$ & $p>0,05$ & $3,205 \times 10^{7} \pm 9 \times 10^{6} \mathrm{CFU} / \mathrm{g}$ & $5,015 \times 10^{6} \pm 8,86 \times 10^{5} \mathrm{CFU} / \mathrm{g}$ & $\mathrm{p}<0,01$ \\
\hline $\begin{array}{l}\text { Opportunistic } \\
\text { enterobacteria }\end{array}$ & $1,555 \times 10^{6} \pm 4,36 \times 10^{5} \mathrm{CFU} / \mathrm{g}$ & $5,011 \times 10^{6} \pm 5,61 \times 10^{5} \mathrm{CFU} / \mathrm{g}$ & $p>0,05$ & $1,55 \times 10^{4} \pm 3,1 \times 10^{3} \mathrm{CFU} / \mathrm{g}$ & $1,5024 \times 10^{8} \pm 3,4 \times 10^{7} \mathrm{CFU} / \mathrm{g}$ & $p<0,001$ \\
\hline
\end{tabular}


in the degree of intestinal dysbiosis in patients of the main and control groups ( $p>0.05)$. After treatment in the main group, in comparison with the control group, there was an increase in the number of patients with the normal intestinal microflora (14 patients - 70\%) as well as a decrease in the number of patients with intestinal dysbiosis with an obvious statistically significant difference $(p<0.001)$.

\section{Discussion}

There are studies in the already existed scientific literature which dwell on the usage of probiotics only enterally [15], [16], [17], [18]. Shen et al. investigated the number of lactobacilli, probiotic bacteria, and bifidobacteria in 30 children with Hirschsprung disease (10 without enterocolitis, 20 with enterocolitis) and 15 healthy children in the control group. They found a statistically significant decrease in the level of probiotic bacteria in all 30 children and, moreover, revealed that the number of bifidobacteria is lower in patients with enterocolitis compared with patients without enterocolitis. Based on this, the authors concluded that a deficiency of bifidobacteria and lactobacilli in patients with enterocolitis may lead to a decrease in the barrier function of the intestinal epithelium and may be a predisposing factor in the development of HAEC; hence, treatment with prebiotics or probiotics of such patients may have a positive result [19].

However, there are studies that reject such a conclusion. For example, El-Sawaf et al. involved 32 patients with Hirschsprung's disease to his study, they took the probiotics orally and after the calculations of the results, the authors concluded that taking probiotics does not reduce the risk of developing HAEC [20].

Against this background, the surveys on the implication of siphon enema and drug enema in the prevention of HAEC are not found at all. Hence, the use of probiotics by drug enema to reduce the risk of developing HAEC is a completely new way of treatment. The patent for the invention of the "Method for the prevention of HAEC in children" (No. 32679, dated 01.29 .2018 by the Ministry of Justice of the Republic of Kazakhstan) was obtained for the developed method.

\section{Limitation}

The effectiveness of the developed method is reduced within Hirschsprung's disease patients with an intestinal stoma since the presence of an intestinal stoma makes it difficult to perform a medicinal enema with probiotics of full value. Non-positive results might be obtained.

\section{Conclusions}

The usage of the developed method of biocenosis correction allows managing the negative effect of siphon enemas and normalizing the ratio of microorganisms inhabiting the large intestine. The method of preventing the inflammatory process in the intestine - HAEC - in accordance with the developed method of correcting the quantitative composition of the intestinal microflora by syphon enemas and probiotics is effective and can be introduced into clinical practice.

\section{References}

1. Kenny SE, Tam PK, Garcia-Barcelo M. Hirschprung's disease, Semin Pediatr Surg. 2010;19(3):194-200.

PMid:20610192

2. McKeown SJ, Stamp L, Hao MM, Young HM. Hirschsprung disease: A developmental disorder of the enteric nervous system. Wiley Interdiscip Rev Dev Biol. 2013;2(1):113-29. https://doi.org/10.1002/wdev.57

PMid:23799632

3. Langer JC. Hirschsprung disease. Curr Opin Pediatr. 2013;25(3):368-74.

PMid:23615177

4. Kholostova VV. Surgical Treatment of Hirschsprung's Disease in Children: Doctor of Medical Sciences. Moscow: Pirogov Russian National Research University; 2015.

5. Krivcheniya DY, Khursin VN, Pritula VP. Enterocolitis in hirschsprung disease. Immunohistological features, pathogenesis, clinic, treatment. Ukr Med J. 2001;5(25):10.

6. Baranovskiy AY. Fundamentals of Nutrition of Russians: Therapeutic Starvation. Nutrition and Pregnancy, Eating after Surgery, Therapeutic Nourishment Diets Food Intolerance. St. Petersburg: Peter; 2007.

7. Bondarenko VM. Dysbacteriosis of the Intestine as a Clinical and Laboratory Syndrome: The Current State of the Problem. Manual for Doctors. Moscow: GEOTAR-Media; 2007.

8. Gosain A, Brinkman AS. Hirschsprung's associated enterocolitis. Curr Opin Pediatr. 2015;27(3):364-9.

PMid:25944307

9. Austin KM. The pathogenesis of Hirschsprung's diseaseassociated enterocolitis. Semin Pediatr Surg. 2012;21(4):319-27. PMid:22985837

10. Lenyushkin Al. Surgical Coloproctology of Childhood. Moscow: Medicine; 1999.

11. Kivva AN. Monitoring of the level of endogenous intoxication in Hirschsprung's disease in children. Child Surg. 2001;6:15-7.

12. Kolomeitsev PA. Chronic constipation. Bull Surg. 1999;158(6):52.

13. Reid JR. The barium enema in constipation comparison with rectal manometry and biopsy to exclude Hirschsprung's disease after the neonatal period. Padiatr Radiol. 2000;30(10):681-4. https://doi.org/10.1007/s002470000298 PMid:11075600

14. Sectoral Standard "Protocol of Treatment. Intestinal Dysbiosis. No. 231 from 9.06.2003. Order of the Ministry of Health of Russian Federation. Available from: https://www.evrika.ru/ federal-standards/620. [Last accessed on 2019 May 20] 
15. Ursova NI. In: Rimarchuk GV, editor. Disturbance of Microflora and Dysfunction of the Biliary Tract in Children: A Guide for Practicing Doctors. Moscow: Prototype; 2005.

16. Fuller R. Probiotics in man and animals. J Appl Bacteriol. 1989;66(5):365-78.

PMid:2666378

17. Elisseyev YY. Violation of Intestinal Microflora (Dysbacteriosis), Childhood Diseases. Moscow: Litres; 2008.

18. Dysbacteriosis. Mythical Diagnosis. Health by Nature; 2012. Available from: http://www.russianweek.ca/articles/experts-advice/ staroverskaya/disbakterioys. [Last accessed on 2020 April 20].
19. Shen DH, Shi GR, Chen JJ. Detection of intestinal bifidobacteria and lactobacilli in patients with Hirschsprung's disease associated enterocolitis. World J Pediatr. 2009;5(3):201-5. https://doi.org/10.1007/s12519-009-0038-x

PMid:19693464

20. El-Sawaf M, Siddigui S, Mahmoud M. Probiotic prophylaxis after pullthrough for Hirschsprung disease to reduce incidence of enterocolitis: A prospective, randomized, double-blind, placebocontrolled, multicenter trial. J Pediatr Surg. 2013;48(1):111-7. https://doi.org/10.1016/j.jpedsurg.2012.10.028

PMid:23331802 